\title{
Cod and climate: effect of the North Atlantic Oscillation on recruitment in the North Atlantic
}

\author{
Leif Chr. Stige ${ }^{1}$, Geir Ottersen ${ }^{2,6}$, Keith Brander ${ }^{3}$, Kung-Sik Chan ${ }^{4}$, \\ Nils Chr. Stenseth ${ }^{1,5}$ \\ ${ }^{1}$ Centre for Ecological and Evolutionary Synthesis (CEES), Department of Biology, University of Oslo, \\ PO Box 1066 Blindern, 0316 Oslo, Norway \\ ${ }^{2}$ Institute of Marine Research, PO Box 1870, 5817 Bergen, Norway \\ ${ }^{3}$ International Council for the Exploration of the Sea, Palægade 2-4, 1261 Copenhagen K, Denmark \\ ${ }^{4}$ Department of Statistics and Actuarial Science, University of Iowa, 263 Schaeffer Hall, Iowa City, Iowa 52242, USA \\ ${ }^{5}$ Department of Coastal Zone Studies, Institute of Marine Research, Flødevigen Marine Research Station, 4817 His, Norway \\ ${ }^{6}$ Present address: Centre for Ecological and Evolutionary Synthesis (CEES), Department of Biology, University of Oslo, \\ PO Box 1066 Blindern, 0316 Oslo, Norway
}

\begin{abstract}
The impact of the environment on interannual variability in fish recruitment has proven difficult to establish empirically, and environment-recruitment correlations have often been found to break down when more data become available. This may suggest that the statistical models have failed to capture the essential explanatory variables, or that environment-recruitment relationships are non-stationary, and thus actually change. The present paper explores the effect of climate, measured by the North Atlantic Oscillation (NAO), on the recruitment of North Atlantic cod Gadus morhua. The literature on the topic is reviewed and compared with results from a new analysis, in which data from all 22 main stocks are combined in 1 overall model. Results of the new analysis demonstrate (i) a geographic pattern in the effect of the NAO on recruitment, which resembles the geographic pattern of the correlation between the NAO and sea surface temperature, and (ii) trends in recruitment levels as well as in the effects of climate. These trends are not fully explainable through changes in spawning stock biomass. Summarizing the old and new insights, we arrive at the following general conclusions: NAO affects cod recruitment through local environmental variables such as sea temperature, salinity, oxygen, turbulence and advection. Cod recruitment is densitydependent, although the new analysis does not unequivocally support the existence of general patterns of density-dependent climate effects. There are trends in cod recruitment and in the relationship between climate and recruitment, possibly caused by demographic changes in the cod stocks (e.g. fishing-induced) and changes in the biotic or abiotic environment (regime shifts).
\end{abstract}

KEY WORDS: Fish recruitment - Climate effect ' Non-stationarity · Density-dependence · Gadus morhua Resale or republication not permitted without written consent of the publisher

\section{INTRODUCTION}

\section{The elusive effects of climate}

The influence of the weather on fish production has long attracted the interest of fishermen and scientists alike (Helland-Hansen \& Nansen 1909, Cushing 1982, also see Stenseth et al. 2004). Climate variability may influence the abundance of catchable fish, principally through effects on recruitment (how many young fish survive sufficiently long to enter the segment of the stock being exposed to the fishery) (Ottersen et al. 2004). Climate impacts on recruitment may occur through a suite of different physical and biological processes, mainly related to effects of temperature, salinity, oxygen, turbulence and advection (reviewed by Ottersen et al. 2004). Identification of the climatic factors which are important for recruitment has, how- 
ever proven difficult to establish empirically: reported environment-recruitment correlations have often been found to break down when more information becomes available (Drinkwater \& Myers 1987, Myers 1998). A notable exception is temperature effects near species' northern or southern distributional ranges, which have generally been found to be consistent upon retesting.

One possible explanation for the breakdown of correlations is that the models have failed to capture the essential explanatory variables. This is not unlikely, as the statistical modelling is complicated by the correlation among the explanatory variables and the limited number of years for which data are available for any given stock. Alternatively, the environmental effects may be non-stationary: the nature of the relationship between fish recruitment and the physical environment may vary over time (Ottersen et al. 2004). For example, because cod have been heavily exploited by fisheries, many stocks have declined during recent decades. This has resulted in reductions in spawning stock biomass as well as in demographic changes (younger average age, fewer age classes, reduced age at maturity) (ICES 2005b) - changes which may have affected mean recruitment levels as well as the sensitivity of recruitment to climatic variability (Brander 2005, Ottersen et al. 2006). Further, non-linearity in the relationship between recruitment and environmental factors might lead to (apparent) non-stationarity on a linear scale. For example, with a dome-shaped relationship between recruitment and wind speed (Cury \& Roy 1989), a shift from a low-wind to a high-wind regime could hypothetically lead to a change from positive to zero or negative recruitment-wind speed correlations. Disentangling these alternative explanations for the breakdown of correlations requires, besides proper data treatment, analysis of long data series - or if such data do not exist, that data from many stocks are compared in a unified analysis (as done, e.g. by Myers \& Barrowman 1996, Myers 1998, Planque \& Frédou 1999, Brander \& Mohn 2004).

Indices of large-scale climatic phenomena such as the North Atlantic Oscillation (NAO) (Hurrell 1995) are often found to account for ecological processes better than local weather variables. They can do so because they reduce complex space and time variability into simple measures (Stenseth et al. 2003, Hallett et al. 2004, Stenseth \& Mysterud 2005). As suggested by Stenseth \& Mysterud (2005) such indexes might properly be seen as 'weather packages'. The NAO quantifies large-scale atmospheric fluctuations between the subtropical and sub-polar regions of the North Atlantic, determining the speed and direction of the prevailing westerly winds. It is the dominant mode of atmospheric behaviour in the North Atlantic throughout the year, although it is most pronounced during winter, the season of strongest pressure gradients and interannual variability (Moses et al. 1987, Cayan 1992). A positive NAO phase is associated with strong wind circulation in the North Atlantic, high atmospheric and sea temperatures in western Europe and low temperatures on the east coast of Canada (Fromentin \& Planque 1996, Parsons \& Lear 2001). Through these environmental variables the NAO has been shown to have impacts on plankton, fish and shellfish in the North Atlantic (reviewed by Parsons \& Lear 2001, Drinkwater et al. 2003).

Atlantic cod Gadus morhua is among the commercially most important fish species in the North Atlantic, although many of the stocks are now at historically low levels because of over-fishing (Myers et al. 1996, ICES 2005b). Understanding how climate affects recruitment of cod is important, because it may allow for better management of the stocks (Planque \& Frédou 1999, Brander \& Mohn 2004). In addition, because changes in the NAO are being investigated as part of global-climate modelling (Gillett et al. 2003), understanding how the NAO affects cod recruitment may also indicate how the cod stocks will be affected by future climate change.

A number of earlier studies have considered links between the NAO and cod recruitment in the North Atlantic. We will first review the literature, secondly formulate new research questions, thirdly try to answer these questions by applying innovative statistical methodology on data from all major North Atlantic cod stocks, and finally use the new insight to synthesize our knowledge about the effects of the NAO on cod recruitment.

\section{Cod recruitment and the NAO: a synoptic account of earlier findings}

In spite of confounding effects of fisheries, several studies have presented compelling support for variation in the cod stocks being linked to the NAO (see Table 1 for an overview of key NAO-cod recruitment papers). The actual term NAO was seldom used in ecological studies until ca. 10 yr ago (Ottersen et al. 2001, Stenseth et al. 2002, Stenseth et al. 2003). However, Izhevskii (1961, 1964), referred to in Rodionov (1995), noted that year-class strength in major fish species seemed to fluctuate out of phase between the eastern and western regions of the North Atlantic and that this was an effect of large-scale climate processes. He described the different regions of the Atlantic as different 'systems of nature'. Also Templeman (1972) noted that good year classes of cod (and haddock) in the North West Atlantic often coincided with poor year classes in the East Atlantic, and vice versa. The importance of the large-scale wind field over the Atlantic was underlined by Dickson \& Brander (1993) who stud- 
Table 1. Key studies linking variability in cod recruitment to the North Atlantic Oscillation (NAO) listed in chronological order. Abbreviations: N, north; $S_{\text {, south; }}$, west; $E_{\text {, east }}$ No., number of stocks studied

\begin{tabular}{|c|c|c|c|c|}
\hline Study area & No. & Method & Main findings & Reference \\
\hline N Atlantic & $\begin{array}{l}\text { Multi- } \\
\text { species }\end{array}$ & $\begin{array}{l}\text { Regression } \\
\text { analysis/review }\end{array}$ & $\begin{array}{l}\text { Out-of-phase E-W fluctuations in } \\
\text { year-class strengths attributed to } \\
\text { large-scale climate processes }\end{array}$ & $\begin{array}{l}\text { Izhevskii }(1961,1964) ; \\
\text { referred to in } \\
\text { Rodionov (1995) }\end{array}$ \\
\hline N Atlantic & $\begin{array}{l}\text { Multi- } \\
\text { species }\end{array}$ & Review & $\begin{array}{l}\text { E-W opposition in year-class } \\
\text { strength }\end{array}$ & Templeman (1972) \\
\hline N Atlantic & 6 & Review & $\begin{array}{l}\text { Variability in recruitment linked } \\
\text { to slow shifts in the Atlantic- } \\
\text { scale wind field }\end{array}$ & $\begin{array}{l}\text { Dickson \& Brander } \\
\text { (1993) }\end{array}$ \\
\hline $\begin{array}{l}\text { Labrador- } \\
\text { NE Newfld. } \\
\text { ('2J3KL') }\end{array}$ & 1 & Review & $\begin{array}{l}\text { Recruitment is enhanced during } \\
\text { negative NAO events (warmer } \\
\text { water) }\end{array}$ & $\begin{array}{l}\text { Mann \& Drinkwater } \\
\text { (1994) }\end{array}$ \\
\hline N Atlantic & 10 & $\begin{array}{l}\text { Factor } \\
\text { analysis }\end{array}$ & $\begin{array}{l}\text { E-W and N-S opposition in year- } \\
\text { class strengths; first factor } \\
\text { tentatively attributed to NAO }\end{array}$ & Rodionov (1995) \\
\hline Skagerrak & 1 & $\begin{array}{l}\text { Mantel correlogram } \\
\text { Time series analysis } \\
\text { Superposed epoch analysis }\end{array}$ & $\begin{array}{l}\text { NAO did not significantly affect } \\
\text { abundance of juvenile cod }\end{array}$ & $\begin{array}{l}\text { Fromentin et al. } \\
\text { (1998) }\end{array}$ \\
\hline Baltic & 1 & $\begin{array}{l}\text { Transfer function } \\
\text { models }\end{array}$ & $\begin{array}{l}\text { NAO affects recruitment through } \\
\text { effects of salinity and oxygen }\end{array}$ & Hänninen et al. (1999) \\
\hline N Atlantic & $\begin{array}{l}\text { Multi- } \\
\text { species }\end{array}$ & Review & $\begin{array}{l}\text { NAO affects marine and terrestrial } \\
\text { ecosystems through many } \\
\text { mechanisms }\end{array}$ & Ottersen et al. (2001) \\
\hline N Atlantic & $\begin{array}{l}\text { Multi- } \\
\text { species }\end{array}$ & Review & $\begin{array}{l}\text { Links between long-term NAO } \\
\text { trends and marine ecosystems }\end{array}$ & Parsons \& Lear (2001) \\
\hline NE Arctic & 1 & $\begin{array}{l}\text { Time series } \\
\text { analysis, correlations }\end{array}$ & $\begin{array}{l}\text { NAO affects recruitment mainly } \\
\text { through wind-driven advection } \\
\text { of warm zooplankton rich } \\
\text { Atlantic water }\end{array}$ & $\begin{array}{l}\text { Ottersen \& Stenseth } \\
(2001)\end{array}$ \\
\hline Skagerrak & 1 & $\begin{array}{l}\text { Funtional data } \\
\text { analysis }\end{array}$ & $\begin{array}{l}\text { NAO significantly affected } \\
\text { mean length of juvenile cod }\end{array}$ & Lekve et al. (2002) \\
\hline N Atlantic & $\begin{array}{l}\text { Multi- } \\
\text { species }\end{array}$ & Review & $\begin{array}{l}\text { Strong association between NAO } \\
\text { and changes in several } \\
\text { trophic levels across N Atl. }\end{array}$ & $\begin{array}{l}\text { Drinkwater et al. } \\
(2003)\end{array}$ \\
\hline N Atlantic & 13 & $\begin{array}{l}\text { Time series } \\
\text { analysis }\end{array}$ & $\begin{array}{l}\text { NAO significantly affected } \\
\text { recruitment in } 4 \text { stocks. The signs } \\
\text { of the effects across stocks } \\
\text { resembled geographic pattern of } \\
\text { NAO-sea temperature correlations }\end{array}$ & $\begin{array}{l}\text { Brander \& Mohn } \\
(2004)\end{array}$ \\
\hline $\begin{array}{l}\text { NE Atlantic } \\
\left(\mathrm{S} \text { of } 62^{\circ} \mathrm{N}\right)\end{array}$ & 6 & $\begin{array}{l}\text { Frequency } \\
\text { analysis }\end{array}$ & $\begin{array}{l}\text { NAO effects on recruitment } \\
\text { strongest at low stock biomass }\end{array}$ & Brander (2005) \\
\hline $\begin{array}{l}\text { Baltic and } \\
\text { N Sea }\end{array}$ & $\begin{array}{l}\text { Multi- } \\
\text { species } \\
(2 \text { cod })\end{array}$ & Review & $\begin{array}{l}\text { Switch in the NAO led to synchro- } \\
\text { nus regime shifts also affecting } \\
\text { cod recruitment }\end{array}$ & Alheit et al. (2005) \\
\hline NW Atlantic & $\begin{array}{l}\text { Multi- } \\
\text { species } \\
(2 \text { cod })\end{array}$ & $\begin{array}{l}\text { Generalized } \\
\text { additive model }\end{array}$ & $\begin{array}{l}\text { NAO (lag } 2 \text { yr) significantly } \\
\text { affected recruitment for } 9 \text { of } 12 \\
\text { groundfish stocks studied }\end{array}$ & $\begin{array}{l}\text { Brodziak \& O'Brien } \\
(2005)\end{array}$ \\
\hline
\end{tabular}

ied cod stocks at Iceland, Greenland, Labrador, the Faroes, the Barents Sea and the Baltic. Although the mechanisms differed between stocks, the variability observed could in each case be linked to the same slow shifts in the Atlantic-scale wind field.

One of the very first authors to use the actual NAO in an ecological setting was Rodionov (1995), who docu- mented an east-west and a north-south opposition in year-class strengths of 10 North Atlantic cod stocks by means of factor analysis. The first factor was tentatively explained through atmospheric teleconnections, especially the NAO, the second through differential responses to large-scale temperature changes. Ottersen et al. (2001), Parsons et al. (2001) and Drinkwa- 
ter et al. (2003) reviewed the impact of the NAO on a number of different species and stocks including several cod populations. Recently Brander \& Mohn (2004) demonstrated significant NAO effects on cod recruitment in 4 of 13 North Atlantic stocks investigated. They also found that the estimated signs of the effects in the different stocks showed geographic patterns, resembling the geographic pattern of NAO-SST correlations. Using data from 6 East Atlantic stocks south of $62^{\circ} \mathrm{N}$, Brander (2005) found that the effect of NAO was strongest when stock biomass was low. The influence of the NAO on recruits per spawner anomalies of 12 New England groundfish stocks, including Georges Bank and Gulf of Maine cod, was examined by Brodziak \& O'Brien (2005). By means of generalized additive modelling they analysed the effects of NAO at lags 0,1 and $2 \mathrm{yr}$. They found that the NAO index at a lag of $2 \mathrm{yr}$ was the best single predictor, being statistically significant for 9 out of the 12 stocks.

A number of authors have examined the impact of the NAO on 1 or 2 particular cod stocks (e.g. Solow 2002). The NAO affects the Northeast Arctic cod in the Barents Sea through local sea temperature: positive NAO phases are associated with above average sea temperature, which positively affects recruitment. However, as positive temperature anomalies are linked to advection of warmer zooplankton-rich Atlantic water masses from the southwest, the NAO also works through the regional wind field (Dippner \& Ottersen 2001, Ottersen \& Stenseth 2001). Recruitment of cod in the Baltic Sea, the largest brackish water body in the world, depends on favourable salinity and oxygen conditions in the deeper basins that determine the survival rates of eggs, larvae, and juveniles (Bagge \& Thurow 1994, Jarre-Teichmann et al. 2000). Dickson \& Brander (1993) concluded that inflow of saline and oxygenated water through the Kattegat driven by persistent westerly winds is a crucial factor for cod recruitment in the Baltic. Hänninen et al. (1999) supported the importance of fluctuations in the large-scale atmospheric circulation and emphasised that major pulses of saline water most often occur during winter. They pointed to the combined effect of diminished river runoff and increased intensity of westerly winds, driven by the NAO. Alheit et al. (2005) showed that both the central Baltic and the North Sea underwent regime shifts affecting cod in the late 1980s. They further suggested that these synchronous events were mediated by a switch from a negative to a positive NAO index. On a longer time scale, the positive NAO trend from the 1960s to the 1990s can explain at least part of the switch from high to low gadoid production in the North Sea during the same period (Parsons \& Lear 2001). On the other hand, in the neighbouring Skagerrak area long-term fluctuations in the abundance of juvenile cod were not found to be linearly or non-linearly connected to the NAO (Fromentin et al. 1998); although mean length of the juveniles was positively correlated with the NAO (Lekve et al. 2002). Recruitment to the once large Labrador-Northeast Newfoundland cod stock has been shown to be enhanced during negative NAO events leading to warmer waters (Mann \& Drinkwater 1994).

From the review above we conclude that considerable information on the effects of NAO on cod recruitment already exists. However, our knowledge is still patchy, and no one has yet attempted to analyze all populations in one overall model. Our approach of applying one common model to data from all major North Atlantic cod stocks facilitates comparisons across stocks. We utilize the model to test for geographic patterns in the effects of year-to-year fluctuations in the NAO, and assess whether these effects are non-stationary, and if they are, whether non-stationarity arises because NAO effects depend on spawning stock biomass (Brander 2005), because NAO effects are non-linear, or because NAO effects interact with unmeasured physical or biological factors varying at decadal to multi-decadal scales. The latter may, for example, be community shifts, or changes in the effects of the NAO on the local climate.

\section{MATERIAL AND METHODS}

Recruitment data were obtained for all 22 major North Atlantic cod stocks (Table 2; see also Fig. 1). We used estimates of spawning stock biomass (SSB) and annual numbers of recruits (R) from sequential population analysis (SPA), based on data from commercial fisheries. On average, each recruitment data series spanned 33 yr (range 18 to $56 \mathrm{yr}$ ). (Plots of SSB and R for each stock are included in the Electronic Appendix: www.int-res.com/ articles/suppl/m325p227_app.pdf, Fig. A1).

We used the winter PC-based NAO index of Hurrell (1995, www.cgd.ucar.edu/cas/jhurrell/indices. data.html\#naopcdjfm), which is the principal component time series of the leading eigenvector of seasonal (December through March) sea level pressure anomalies over the Atlantic Sector (20 to $80^{\circ} \mathrm{N}, 90^{\circ} \mathrm{W}$ to $\left.40^{\circ} \mathrm{E}\right)$. Because there are trends in both recruitment and NAO, we also considered effects of a detrended NAO index (Fig. 2). The detrended NAO index was defined as the residuals from a generalized additive model (GAM, Hastie \& Tibshirani 1990), the response variable being NAO, and the predictor a smooth function of year (natural cubic spline with the number of degrees of freedom fixed to 4 : i.e. 5 knots). We analysed models with 0,1 or 2 yr time lag of the NAO effect on recruitment. 
Table 2. Recruitment data used in the analysis. Code: NAFO/ICES code, Range: data range, years with data available on both spawning stock biomass and recruitment (back-calculated to spawning year), Age: recruit age, Location: spawning location (from Myers 2005 and ICES 2005b)

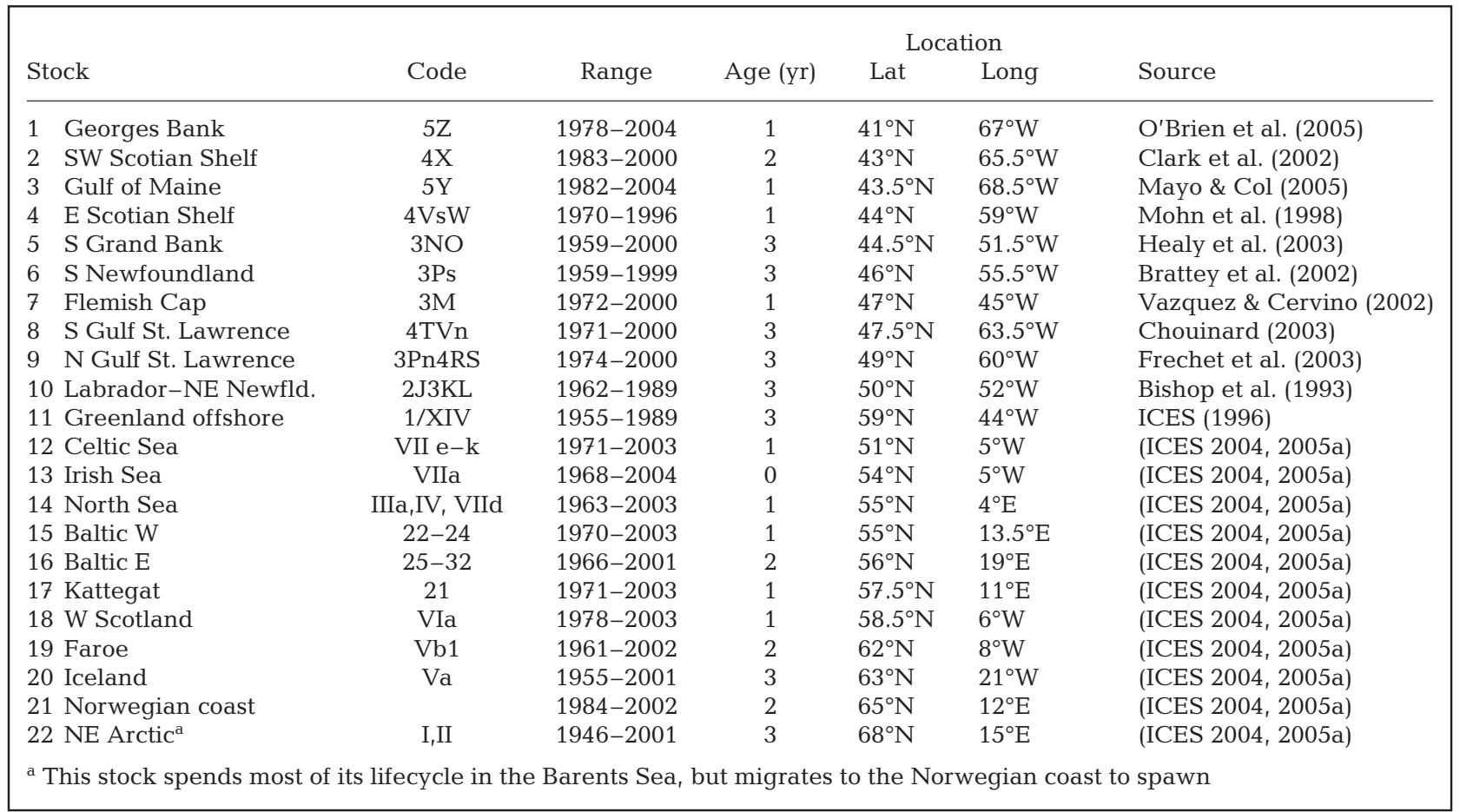



Fig. 1. Spawning locations of cod stocks (numbers; cf. Table 2) and a schematic diagram of the North Atlantic Oscillation (NAO). During a positive NAO phase, westerly winds increase in strength $(+)$, while easterly winds decrease $(-)$. A negative NAO phase has the opposite effect. The coloured dots indicate Pearson's coefficients of correlation between the NAO index and sea surface temperatures January to June $1946-2004$ on a $2^{\circ} \times 2^{\circ}$ grid. Note that while Northeast Arctic cod (22) spawns near the Norwegian coast, it spends most of its lifecycle in the Barents Sea 


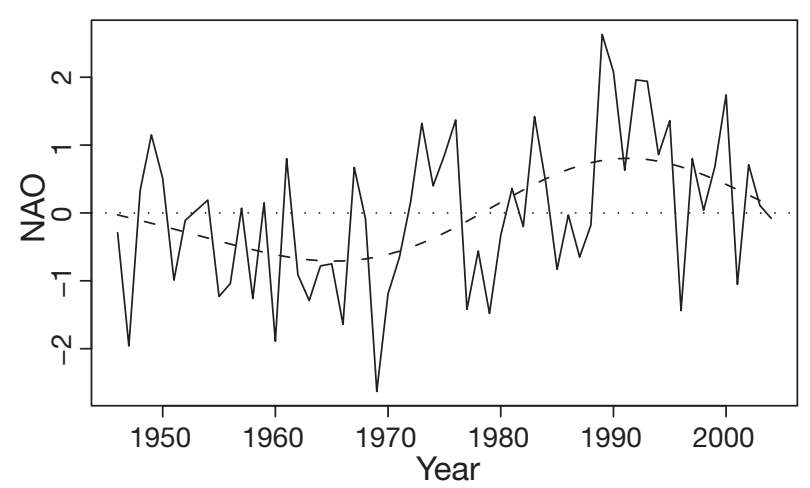

Fig. 2. The PC-based winter (December through March) North Atlantic Oscillation (NAO) index 1946-2004. The detrended NAO index refers to the deviations around the broken line, which is a smooth function of year with $\mathrm{df}=4$

To investigate the relationship between the NAO and sea surface temperatures (SST), North Atlantic monthly mean SST on a $2^{\circ} \times 2^{\circ}$ grid for January to June 1946 to 2004 were extracted from the International Comprehensive Ocean-Atmosphere Data Set (ICOADS) of the National Center for Atmospheric Research, Boulder.

In the statistical analysis, the logarithm of the ratio between the annual numbers of recruits and spawning stock biomass was used as response. Note that although we use a relative measure of recruitment, we will for brevity generally only write 'recruitment' when referring to our results. According to the Ricker model (Ricker 1954), this ratio is a linear function of spawning stock biomass (with coefficients $\mathrm{a}, \mathrm{b}$ ):

$$
\log _{e}(R / S S B)=a+b \text { SSB }
$$

It has been argued that using the R/SSB ratio as response when no significant relation between $R$ and SSB exists, may mask possible recruitmentenvironment relationships (Cardinale \& Hjelm 2006). Although $\log _{\mathrm{e}}(\mathrm{R} / \mathrm{SSB})$ was response in our model, the inclusion of a stock-specific SSB term allowed modelling near zero responses to SSB, and the results were robust to this potential problem (as was supported using alternative methods; see Electronic Appendix).

Data from all stocks were analysed in one GAM, using the mgcr library of R (Wood 2001). The optimal roughness of the smooth terms was estimated by minimizing the generalized cross validation (GCV, Wood 2001, 2004a, see also Electronic Appendix). The GCV of a model is a proxy for the model's out-of-sample predictive mean squared error. Therefore, a model with lower GCV has more explanatory power, and hence is preferred, compared to a model with higher GCV. Model structure was thus decided by comparing GCV of competing models. Model-choice proceeded in an upwards direction, adding 1 term at a time: firstly auto- regression effects, correcting for autocorrelation in the response variable, secondly year effects, accounting for long-term trends in recruitment not necessarily caused by climatic change (e.g. due to changes in demography, such as age structure, age of maturity, sub-stock structure), and thirdly climate effects, as captured by the NAO index. Finally, it was ascertained that none of the terms could be removed from the final model without increasing the GCV. The best model with fixed NAO effects (not depending on SSB or year) was:

$\log _{\mathrm{e}}\left(\mathrm{R}_{i, j} / \mathrm{SSB}_{i, j}\right)=\mathrm{a}_{i}+\mathrm{b}_{i} \mathrm{SSB}_{i, j}+\mathrm{C}_{i} \log _{\mathrm{e}}\left(\mathrm{R}_{i, j-1} / \mathrm{SSB}_{i, j-1}\right)$
$+\mathrm{d}_{i}($ Year $)+\mathrm{eNAO}_{j}+\mathrm{f}\left(\right.$ Long $_{i,}$ Lat $\left._{i}\right) \mathrm{NAO}_{j}+\varepsilon_{i, j}$

Here $\log _{\mathrm{e}}\left(\mathrm{R}_{i, j} / \mathrm{SSB}_{i, j}\right)$ is the response for stock $i$ in year $j$. The stock-specific constants $\mathrm{a}_{i}$ and $\mathrm{b}_{i}$ quantify the steepness and the nonlinearity of the relationship between R and SSB. Non-Ricker type response was also considered, by substituting the $\mathrm{b}_{i}$ term with a stock-specific smooth term of SSB. The constant $\mathrm{C}_{i}$ is a stock-specific auto-regressive term. A common autoregressive term for all stocks, or auto-regressive terms of order higher than 1 did not give as good fit. By including the $\mathrm{c}_{i}$ term, the residuals are largely uncorrelated over time, as there are just 18 significant, moderately large residual autocorrelations out of 330 autocorrelations examined, which is well within the expectation of about 17 false positives (Fig. A2 in Electronic Appendix). The term $\mathrm{d}_{i}$ denotes a stock-specific smooth effect of year (natural cubic spline with maximally $3 \mathrm{df}$ ). The term $\mathrm{f}$ denotes a smooth function of the longitude and latitude of the spawning location of each stock (thin-plate regression spline with maximally $11 \mathrm{df}$ ). Added to the constant e (included for model identification purposes because all additive functions including $f$ have zero mean over the data, Wood 2004a), this term represents the slope of the linear effect of the NAO at each location. This allows the model to incorporate gradual changes between locations in the effect of the NAO, and to identify regions with similar responses without having to make any subjective judgements. A stock-specific NAO effect (i.e. no geographic pattern in the effect) was also considered, but did not give as good fit. Finally, $\varepsilon_{i, j}$ is a noise term of zero mean and finite variance.

We fitted the following model to test for non-stationarity in the NAO effect - that is, to test whether the NAO effect depended on year:

$$
\begin{aligned}
& \log _{\mathrm{e}}\left(\mathrm{R}_{i, j} / \mathrm{SSB}_{i, j}\right)=\mathrm{a}_{i}+\mathrm{b}_{i} \mathrm{SSB}_{i, j}+\mathrm{C}_{i} \log _{\mathrm{e}}\left(\mathrm{R}_{i, j-1} / \mathrm{SSB}_{i, j-1}\right) \\
& \quad+\mathrm{d}_{i}(\text { Year })+\mathrm{eNAO}_{j}+\mathrm{f}\left(\mathrm{Long}_{i,} \text { Lat }_{i}\right) \mathrm{NAO}_{j} \\
& +\mathrm{g}\left(\text { Year }_{j} \text { Long }_{i,} \text { Lat }_{i}\right) \mathrm{NAO}_{j}+\varepsilon_{i, j}
\end{aligned}
$$

The $\mathrm{g}$ term is a tensor-product smooth function constructed from linear combinations of terms that are 
a cubic regression spline basis function of Year and a thin-plate regression spline basis function of longitude and latitude (maximum $\mathrm{df}=5$ and 11, respectively, for Year and Long, Lat splines) (see Wood 2004b). To test whether the NAO effect depended on spawning stock biomass, the following model was considered:

$$
\begin{aligned}
& \log _{\mathrm{e}}\left(\mathrm{R}_{i, j} / \mathrm{SSB}_{i, j}\right)=\mathrm{a}_{i}+\mathrm{b}_{i} \mathrm{SSB}_{i, j}+\mathrm{C}_{i} \log _{\mathrm{e}}\left(\mathrm{R}_{i, j-1} / \mathrm{SSB}_{i, j-1}\right) \\
& \quad+\mathrm{d}_{i}(\text { Year })+\mathrm{eNAO}_{j}+\mathrm{f}\left(\mathrm{Long}_{i} \text { Lat }_{i}\right) \mathrm{NAO}_{j} \\
& +\mathrm{g}\left(\mathrm{SSB}_{\mathrm{ST} i, j} \text { Long }_{i} \text { Lat }_{i}\right) \mathrm{NAO}_{j}+\varepsilon_{i, j}
\end{aligned}
$$

where $\mathrm{SSB}_{\mathrm{ST}}$ is $\mathrm{SSB}$ standardised to maximum = 1 for each stock. The $\mathrm{g}$ term is a tensor-product smooth function similar to that described above, but with $\mathrm{SSB}_{\mathrm{ST}}$ instead of year (maximum df $=3$ for $\mathrm{SSB}_{\mathrm{ST}}$ spline). To test for non-linearity in the NAO effect we fitted a model similar to that given by Eq. (2), except that it also included quadratic NAO terms.

Because the residuals were not homogeneous, but depended in magnitude on SSB and stock, these were weighted in the model fitting. The weights were calculated as the inverse of the fitted values from a linear regression in which the absolute value of the residuals was response and stock and $\log _{\mathrm{e}}(\mathrm{SSB})$ were additive predictor variables. The model was then refitted and the weights refined. This was repeated iteratively until the weights changed by less than $1 \%$ from 1 iteration to the next. None of the standardised residuals (shown in Fig. A3 in the Electronic Appendix) were identified as outliers according to Grubbs' test (Grubbs 1969).

The significance of the effects of NAO was determined non-parametrically using permutation tests. This ensured robustness of the conclusions despite the existence of spatial correlations in recruitment (Myers et al. 1995) not explicitly incorporated in the model used. A first permutation test was based on iterated NAO series. In this test, the NAO index was randomly permutated, substituted with the observed NAO variable in the data set, and the model refitted 1000 times. This gave the null distribution of the test statistic under the scenario of no NAO effect. To test the significance of a fixed NAO effect (Eq. 2) we used the GCV value as a test statistic, because the model included 2 NAO terms and it was not meaningful to test these separately. To test for year- or SSB-dependent NAO effects we used the p-value of the tensor product term in Eq. (3) or (4) as test statistic. A second permutation test was based on historic NAO series. Here, the model was fitted on data sets in which the NAO index was shifted by 5 yr or more. That is, instead of using NAO values for 1945-2004 (the recruitment data range), NAO time series starting each year 1864-1940 were used. The null distribution obtained by this procedure was based on fewer recalculations, but the temporal autocorrelation in the NAO index was retained. In a third permu- tation test, only the deviations around long-term trends in the NAO index (Fig. 2) were permutated and added back to the trend-line; otherwise the test was performed as the first test. Consequently, using this test, the long-term trend in the NAO index was retained in all permutation data sets. The null-hypothesis for the third permutation test was therefore that NAO effects on recruitment were only caused by the long-term trend in the NAO. If rejected, it meant that variability in the detrended NAO index had an effect. Finally, $95 \%$ confidence limits for the effects of NAO and year were computed using a modified wild bootstrap (Liu 1988, Mammen 1993) approach, which was developed to account for heteroskedastic errors. The bootstrap distribution for the effect estimates was obtained by randomly inverting the signs of the errors from the model, adding these to the fitted values, and refitting the model (repeated 1000 times). To account for the spatial correlation, all errors from a given year in a given bootstrap sample were either inverted or not (with probability 0.5).

We also assessed the effects of the NAO using models that did not include auto-regression or year effects. Such models are more sensitive to effects of decadalscale changes in the NAO, at the same time being more susceptible to confounding effects of other factors varying at decadal scales, while the models presented in the results mainly capture the effects of yearto-year changes in the NAO. According to GCV, the 2 sets of models provided similar support for the effect of the NAO and for temporal changes in this effect (Table A1, in the Electronic Appendix).

\section{RESULTS}

\section{Recruitment as a function of stock size}

Other shapes of the R-SSB relationship than the Ricker type were considered by substituting the $\mathrm{b}_{i}$ terms in Eq. (2) with smooth functions of SSB. As the optimally smoothed functions approach straight lines $(\mathrm{df}=1)$, they represent in effect the Ricker response. For 13 stocks, the estimated df of this term was between 1 and 1.01, while for 9 stocks, the estimated df was larger, implying some deviations from the Ricker response for these stocks. The subsequent analyses were therefore done with models based on the Ricker response as well as with models based on the more flexible response. The only exceptions to this were the permutation tests, which were too computationally expensive to run on the non-Ricker based models. Results regarding the effects of the NAO did not differ substantially between the 2 sets of analyses: hence, only results based on the simpler Ricker model are presented. 


\section{Temporal autocorrelation in recruitment}

The response, $\log _{\mathrm{e}}(\mathrm{R} / \mathrm{SSB})$, was auto-correlated with the previous year's response. The auto-regression coefficients ( $c_{i}$ in Eq. 2) varied among stocks. Fourteen of the coefficients were positive, 8 negative (Mean $\mathrm{C}_{i}=$ 0.20 , range $=-0.58$ to 0.71 ). The fact that the autoregressive term could not be removed from the final model without loss of predictive power may indicate that important explanatory variables were missed. However, it should be noted that ageing errors and the like may also lead to autocorrelation in SPA estimates of recruitment (Bradford 1991).

\section{Trends in recruitment}

The inclusion of stock-specific smooth effects of year led to a considerable reduction in GCV (Table 3). For 19 stocks, recruitment appears generally to have decreased with time (Fig. 3). Because of trends in SSB, the estimated effects of SSB and year are confounded, however, and the plots of the year effects should therefore be interpreted cautiously (see Figs. A4 \& A5 in the Electronic Appendix for plots of the combined effects of SSB and year). In particular, the sum of the estimated effects of SSB and year follow the trend of the data well.

\section{No evidence for lagged NAO effects}

Models with lagged NAO effects (1 or 2 yr) had lower explanatory power (higher GCV) than models without such effects (whether or not same-year NAO effects were already included in the model). Only results using same-year NAO effects are therefore pre- sented. Note that this result using a global analysis does not exclude the presence of lagged effects locally - which indeed have been demonstrated in previous studies (e.g. Hjermann et al. 2004, Brodziak \& O'Brien 2005).

\section{Spatial pattern of NAO effects}

There is a clear spatial pattern in the effect of the NAO (Fig. 4), resembling the pattern of the correlation between the NAO and sea surface temperature (Fig. 1). During positive NAO anomalies cod recruitment tends to be lower than normal in the southernmost stocks at both sides of the North Atlantic and higher in the northernmost stocks (vice versa for negative anomalies). A model assuming constant effect of NAO for any given locality had higher explanatory power than a model without NAO effects (Table 3). The permutation tests confirmed that this pattern was unlikely to arise just by chance ( $p=0.05$ and $p=0.06$, respectively, in permutation test [iterated NAO] and permutation test [historic NAO]). The permutation test for the detrended NAO index gave equally strong support $(p=0.05)$, suggesting that the effect was not primarily caused by long-term trends in the NAO.

\section{Non-stationarity of NAO effects}

The effect of the NAO on cod recruitment appears to change at a multi-decadal scale (Fig. 5). For example, in the southern parts of the East Atlantic, NAO effects tended to become increasingly negative from the 1980 s onwards. In most of the West Atlantic, NAO effects tended to become increasingly negative from the late 1960 s to the early 1980s. In Greenland and Iceland, there was a shift from negative to positive effects in the 1960s. The model that incorporated temporal changes in NAO effects had higher explanatory power than models with constant or no NAO effect (Table 3). The permutation tests confirmed the robustness of the result $(\mathrm{p}<0.001, \mathrm{p}<0.013$, and $\mathrm{p}=$ 0.01 , respectively, in permutation tests [iterated NAO, historic NAO, and detrended NAO]). There have also been changes in the correlation between the NAO index and SST in the different areas (Fig. 5). For example, for several West Atlantic stocks, NAO-SST correlations changed from 


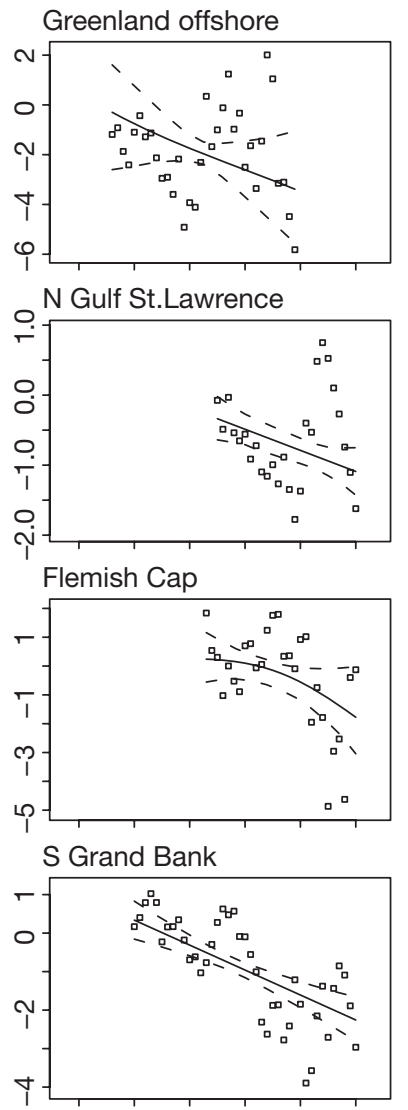

\section{SW Scotian Shelf}

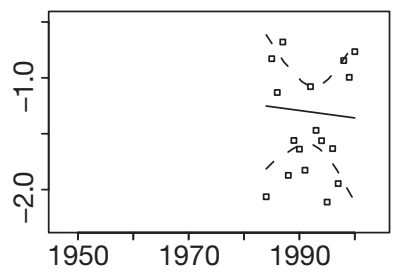

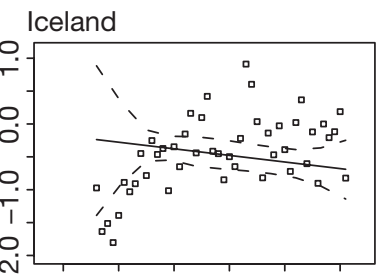

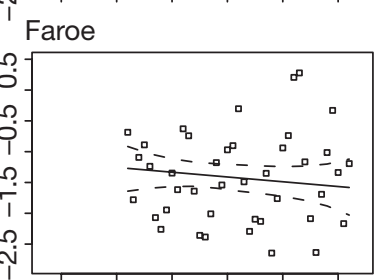

\section{W Scotland}


\section{Baltic W}
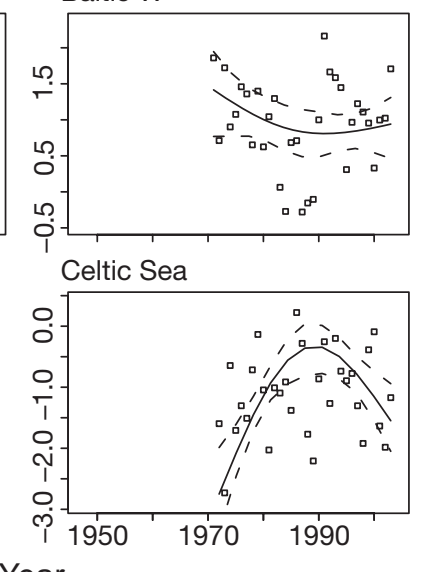

NE Arctic

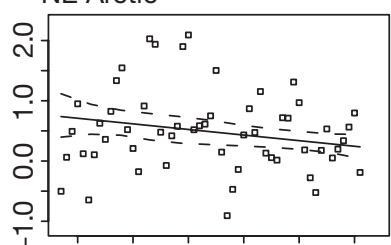

Norwegian coast
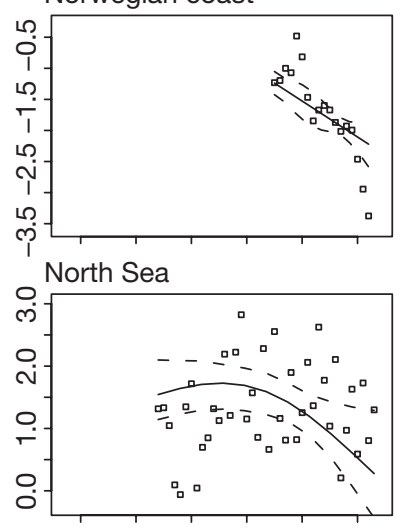

Kattegat

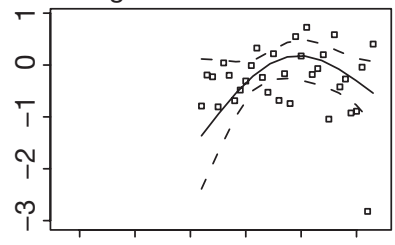

Baltic E

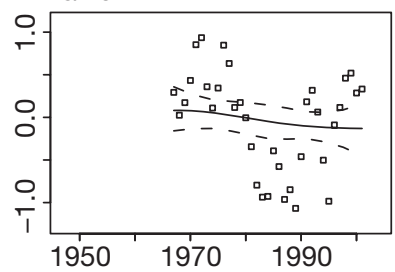

Fig. 3. Trends in recruitment of cod stocks in the North Atlantic. R is annual number of recruits and SSB is spawning stock biomass. Points: observed $\log _{e}(\mathrm{R} / \mathrm{SSB})$. Lines: smooth effects of year with $95 \%$ bootstrap confidence limits. Year effects were estimated using a generalized additive model also accounting for effects of SSB and the North Atlantic Oscillation (NAO) (Eq. 2). Predictions for mean SSB in each stock and NAO $=0$ are shown. Because of trends in SSB, the effects of year and SSB are partly confounded. Figs. A4 \& A5 in the Electronic Appendix show the combined effects of SSB and year

being weakly negative to weakly positive around 1970. This suggests that the effect of the NAO on the local climate is not fixed.

A model in which the NAO effect depended on spawning stock biomass (Fig. A6, in the Electronic Appendix) had higher explanatory power than a model in which the NAO effect was fixed, but lower than a model with an interaction between the NAO effect and year (Table 3). The permutation tests did not confirm that the pattern was unlikely to arise by chance $(p=0.14, p=0.13$, and $p$ $=0.20$, respectively, for $\mathrm{SSB}_{\mathrm{ST}} \times \mathrm{NAO}$ interaction effect in permutation tests [iterated NAO, historic NAO, and detrended NAO]). Because of trends in spawning stock biomass (Fig. A1, in the Electronic Appendix), the 




Fig. 4. Spatial pattern of the effect of the North Atlantic Oscillation (NAO) on cod recruitment. The isoclines represent the slope of a linear effect of NAO on $\log _{\mathrm{e}}(\mathrm{R} / \mathrm{SSB})$, where R is annual number of recruits and SSB is spawning stock biomass. The plot is based on a model in which the NAO effect is fixed for any given locality (Eq. 2). The points mark the spawning locations of the stocks included in the analysis

interaction between the NAO and spawning stock biomass is statistically confounded with the interaction between the NAO and year. A model including both these interaction terms (not shown) did not have higher explanatory power than a model including only the latter interaction term. It is not possible to separate the 2 effects conclusively from our data.

The temporal change in the NAO effect was not explainable through non-linearity in the effect of the NAO: a model with quadratic NAO effects did not have higher explanatory power than a model with only linear NAO effects (Table 3 ).

\section{DISCUSSION}

\section{Interpretation of modelling results}

By including data from all main North Atlantic cod stocks in one analysis, we can draw general conclusions about the patterns of interannual variability in recruitment. We find that recruitment shows significant, stock-specific trends, that there is a significant geographic pattern in the effect of the NAO on recruitment, and that this climatic effect is non-stationary. The non-stationarity cannot be attributed to nonlinearity in the climate effect. Nor does it seem to be fully explainable through interactions between spawning stock biomass and climate. We will discuss each of these findings below.

Firstly, we find that there are long-term trends in recruitment in each stock, which are not explainable through effects of climate or spawning stock biomass. There are several possible reasons for these trends. (1) Spawning stock biomass is not a very good estimate of a stock's reproductive capacity, but often the best one available. Changes in age and size structure have occurred in most stocks because of fishing (ICES 2005b), and these changes are likely to have affected the recruitment potential. Also changes in the dynamics of the different subpopulations within what is defined as a stock may have affected the recruitment potential. For example, the northernmost subpopulations of the Canadian Northern cod disappeared first, a development that may have been detrimental to the stock as a whole if the northernmost spawning sites are best (deYoung \& Rose 1993). (2) Trends in cannibalism (e.g. driven by changes in the availability of preferred prey) may have led to trends in the natural mortality of juvenile cod. (3) The NAO does not capture all environmental (abiotic and biotic) changes. For example, changed community structure has been invoked as an explanation as to why West Atlantic cod stocks have failed to recover after their collapse in the early 1990s (Frank et al. 2005). Further, there have been considerable changes in zooplankton communities in various parts of the North Atlantic (Beaugrand et al. 2002). More detailed analyses are needed to assess the relative merit of the different possible reasons outlined. For now, we note that statistical correction for the trends allows more precise estimation of the climatic effects on recruitment.

Secondly, our results corroborate the findings of Brander \& Mohn (2004), showing that NAO effects are predominantly of negative sign for the southernmost cod stocks on both sides of the North Atlantic, and of positive sign for the northernmost stocks. This pattern resembles the geographic pattern of the correlation between the NAO and sea temperature (compare Figs. 1 \& 4): as NAO-temperature correlations become progressively more positive towards the south and east, NAO effects on recruitment become progressively more negative. This similarity does not imply that NAO effects on recruitment are generally mediated by temperature alone, as processes such as advection and mixing may be similarly correlated with temperature across large areas. In addition, the fact that the northern and southern stocks are expected to show opposite temperature responses (Planque \& Frédou 1999) suggests that other factors are also involved. 

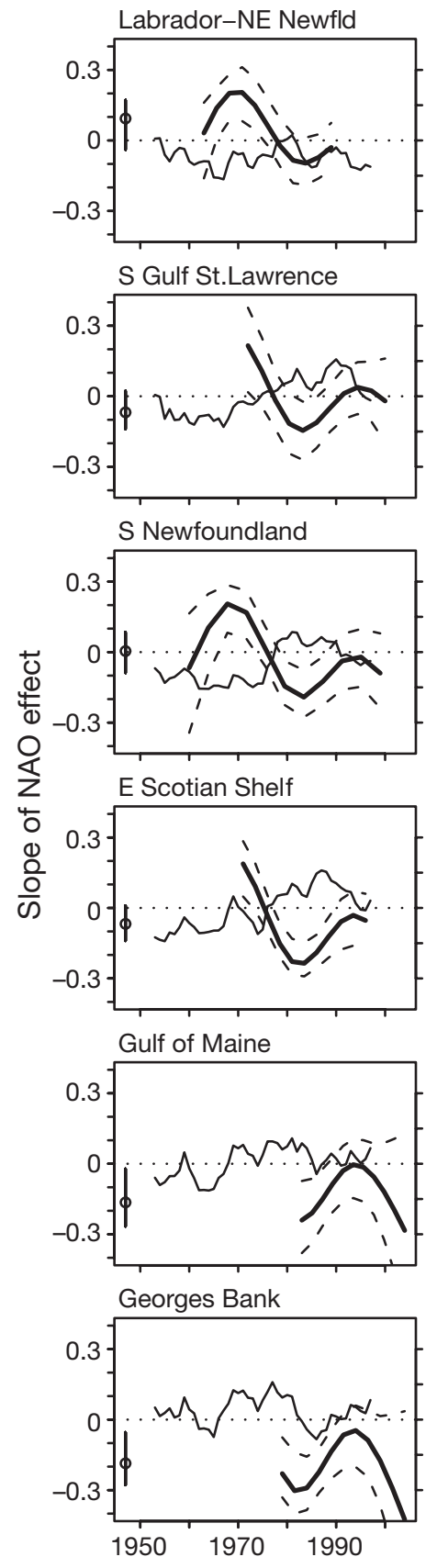

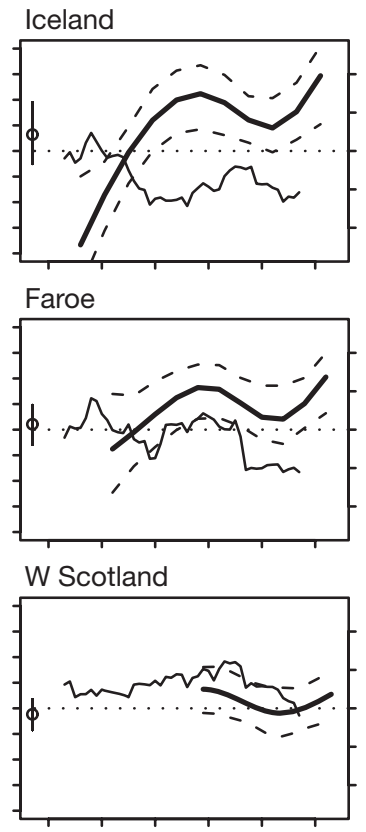

Irish Sea

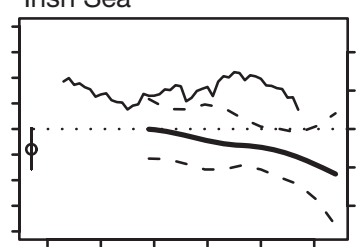

Baltic W
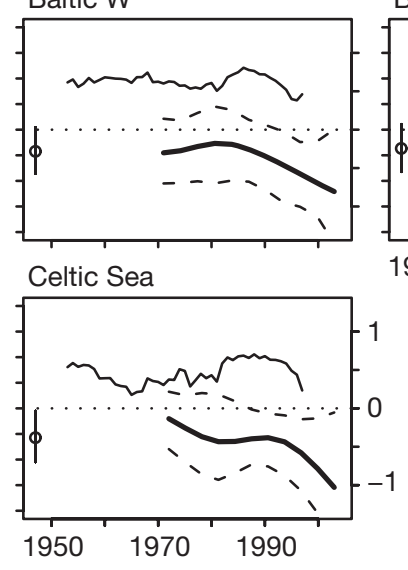



Norwegian coast

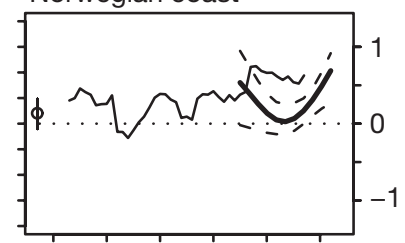

North Sea

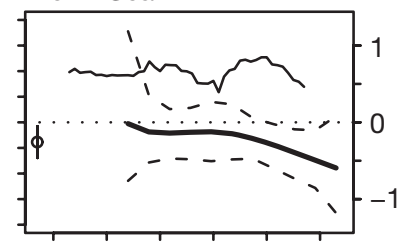

Kattegat



Baltic E

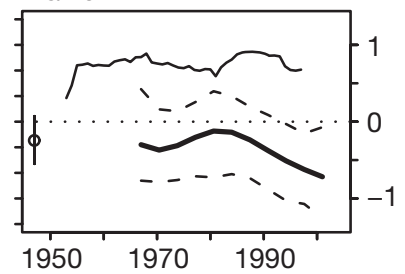

\section{$\frac{0}{D}$
$\frac{\pi}{0}$
$\frac{0}{0}$
0
0
1
0
$\vdots$
$Z$}

Year

Fig. 5. Temporal change in the impact of the North Atlantic Oscillation (NAO) on cod recruitment (loge $[R / S S B] ;$ R: annual number of recruits, SSB: spawning stock biomass). The effect of NAO is modelled to be linear for any given location and year, but the slope of the effect may vary spatially and temporally. Bold and broken lines: estimated slope and $95 \%$ bootstrap confidence bands for spatially and temporally varying NAO effect (Eq. 3). Points and bars: estimated slope and $95 \%$ bootstrap confidence limits for spatially varying NAO effect (Eq. 2; Fig. 4). Thin lines: Pearson's coefficients of correlation between January to June sea surface temperature (SST) at the spawning location $\pm 2^{\circ}$ and the NAO index in $15 \mathrm{yr}$ moving frames centred at the years indicated

Thirdly, we do not find strong evidence for densitydependent climate effects, i.e. for an interaction between the NAO effect and spawning stock biomass. This contrasts with the results of Brander (2005), who found that cod recruitment was most strongly affected by the NAO when stock biomass was low. It should be added that although the interaction effect was not statistically significant in our study, models with densitydependent climate effects did have more explanatory power (lower GCV) than models with fixed climate effects. This might be caused by confounding from the temporally changing NAO effect, but the reverse argu- 
ment could also be invoked. The estimated shapes of density-dependence in our study do not conform well to the results of Brander (2005): climate effects appear equally often to be strongest at high as at low stock size (Fig. A6, in the Electronic Appendix). This discrepancy may be related to the statistical correction for long-term trends in recruitment and for the effects of spawning stock biomass in the present study. We also note that in both studies, the analyses would only be able to detect density-dependent effects shared by stocks geographically close to one another. Our results do not support the existence of general patterns of density-dependent climate effects, but do not exclude the possible existence of such effects within specific stocks.

Fourthly, our results suggest that the effects of the NAO on cod recruitment change at multi-decadal time scales (Fig. 5). This finding implies that the lack of persistency of recruitment-environment correlations (Drinkwater \& Myers 1987, Myers 1998) may reflect true biological or physical changes, rather than being mere statistical artefacts. Several possible reasons, partly related to those proposed for the trends in mean levels of recruitment, exist. (1) Changes in demographic factors may affect the sensitivity of cod recruitment to climate fluctuations. For example, lower mean age of spawners, fewer age classes, shorter spawning season, smaller range in specific gravity of eggs and smaller spawning area are all factors that tend to reduce the distribution of early life stages in space and time - which may make recruitment more vulnerable to environmental variability (Brander 2005, Ottersen et al. 2006). Such changes, whether being phenotypic responses to reduced stock density or effects of fishery-induced evolution (Olsen et al. 2004), might explain the increasingly negative NAO effects in the southern part of the East Atlantic. For other stocks not only the magnitude but also the sign of the NAO effect changes with time. Such shifts in sign could, hypothetically, also be caused by demographic effects (e.g. if the demographic changes led to changes in which life stages were most critical to recruitment). (2) Longterm changes in the biotic or abiotic environment may affect the way interannual variability in a given environmental factor affects cod recruitment. Several studies have described regime shifts in the marine ecosystems in the North Atlantic (reviewed by Weijerman et al. 2005). These shifts include distributional changes in copepod communities (Beaugrand et al. 2002), which are key prey items for juvenile cod. If, for example, there is a longterm shift in dominance between 2 prey species that are differentially affected by interannual variability in the $\mathrm{NAO}$, this might lead to a corresponding shift in the indirect effect of the NAO on cod recruitment. (3) The effect of NAO fluctuations on local environmental variables may change with time. The documented temporal change in the correlation between regional sea temper- atures and the NAO index shows that the relationship between the NAO and local climate is not constant. One possible reason for changes in the impacts of the NAO on local climate is the more eastward position during recent decades of both the northern and southern centres of action of the NAO: the Icelandic low and Azores high pressure zones (Furevik \& Nilsen 2005). In particular the location of the Icelandic low influences the wind field in the region studied in this paper, and through this, oceanographic variables. For several West Atlantic stocks the changes in the correlation between the NAO and sea temperature match the changes in the NAO effects on cod recruitment. In periods when the NAO effect on recruitment is positive for these stocks, the NAOSST correlation tends to be negative, and vice versa, suggesting that the NAO effect is mediated by a negative effect of temperature or a factor correlated with temperature. On the other hand, for the southeastern stocks, we show that the NAO impacts have recently increased in magnitude while the NAO-temperature association remains unchanged. Consequently, the increased sensitivity of recruitment to NAO fluctuations for this region and time period appears unlikely to be mediated through NAO effects on temperature. Note that the increased sensitivity is not explainable through NAO effects on copepods, the key prey items of cod larvae. At the same time as the recruitment to these stocks became increasingly sensitive to NAO fluctuations during the 1990s, the previously established NAO-Calanus connection for the region (Fromentin \& Planque 1996) fell apart (Planque \& Batten 2000). An alternative explanation for this increased sensitivity is that as North Sea wind intensity during late winter has increased in recent decades (Siegismund \& Schrum 2001), the NAO index may to a larger degree track interannual variability in wind-induced advection or mixing during sensitive periods in the life history of cod.

\section{Cod and climate: a synthesis}

Summarizing the literature on the effect of the NAO on recruitment in cod - together with the new results reported in this paper - we conclude, as visualised schematically in Fig. 6, that:

- The NAO affects cod recruitment through regional or local environmental variables such as temperature, salinity, oxygen, turbulence and advectionthe relative importance of which most likely differs among stocks (see studies listed in Table 1).

- There is a clear geographic pattern in the effect of the NAO on cod recruitment (Brander \& Mohn 2004, see also Fig. 4).

- While cod recruitment is affected by direct density dependence, the present study does not unequi- 


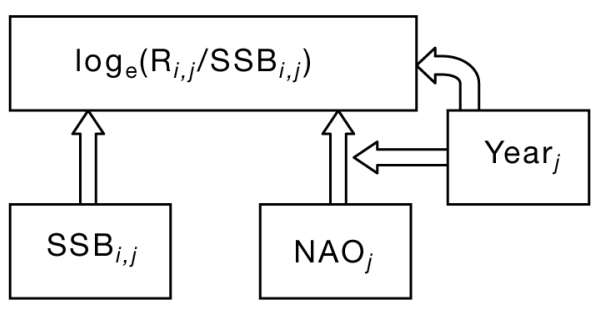

Fig. 6. Conceptual model of the factors affecting the recruitment of a stock, based on the model with highest predictive power for all main North Atlantic cod stocks. R: annual number of recruits. SSB: spawning stock biomass. NAO: North Atlantic Oscillation Index. Subscripts $i$ and $j$ refer to stock and year, respectively. There are temporal changes in recruitment, and in the way the NAO affects recruitment. The density-dependent effects on recruitment are given by the SSB effects on $\log _{e}(\mathrm{R} / \mathrm{SSB})$, which are independent of $\mathrm{NAO}$ and year

vocally support a previous study (Brander 2005) regarding the existence of general patterns of density-dependent climate effects.

- There are strong trends in mean levels of cod recruitment (Fig. 3) as well as in the way the NAO affects recruitment (Fig. 5). Among the possible reasons for these trends are demographic changes in the cod stocks (e.g. fishing-induced) and changes in the biotic or abiotic environment (regime shifts).

That is, although there are several complicating factors, there is a clear location-specific effect of climate variation on cod recruitment in the North Atlantic. Among the unresolved issues are the identification of the underlying causes of the trends in recruitment levels as well as in the climatic effects on recruitment. Further progress may be gained by utilising information on demographic factors, which may be partly responsible for these trends, and to incorporate knowledge about regime shifts in marine systems. Our study demonstrates that the climatic effects on cod recruitment are not stationary, and future studies need to take this into account.

Acknowledgements. The work reported in this paper was made possible through core-funding to CEES. G.O. was supported by the Research Council of Norway through the ECOBE project. We thank Dag Øystein Hjermann, Anne Maria Eikeset and 3 anonymous reviewers for valuable comments and suggestions on the manuscript. This work was done within the framework of the ICES/GLOBEC Cod and Climate Change programme.

\section{LITERATURE CITED}

Alheit J, Mollmann C, Dutz J, Kornilovs G, Loewe P, Mohrholz V, Wasmund N (2005) Synchronous ecological regime shifts in the central Baltic and the North Sea in the late 1980s. ICES J Mar Sci 62:1205-1215
Bagge O, Thurow F (1994) The Baltic cod stock: fluctuations and possible causes. ICES Mar Sci Symp 198:254-268

Beaugrand G, Reid PC, Ibañez F, Lindley JA, Edwards M (2002) Reorganization of North Atlantic marine copepod biodiversity and climate. Science 296:1692-1694

Bishop CA, Murphy EF, Davis MB, Baird JW, Rose GA (1993) An assessment of the cod stock in NAFO Divisions 2J+3KL. NAFO SCR Doc 93/86

Bradford MJ (1991) Effects of ageing errors on recruitment time series estimated from sequential population analysis. Can J Fish Aquat Sci 48:555-558

Brander K (2005) Cod recruitment is strongly affected by climate when stock biomass is low. ICES J Mar Sci 62:339-343

Brander K, Mohn R (2004) Effect of the North Atlantic Oscillation on recruitment of Atlantic cod (Gadus morhua). Can J Fish Aquat Sci 61:1558-1564

Brattey J, Cadigan NG, Healey BP, Lilly GR, Murphy EF, Shelton P, Stansbury DE, Mahé JC (2002) An assessment of the cod (Gadus morhua) stock in NAFO Subdiv. 3Ps in October 2002. CSAS Res Doc 2002/096

Brodziak J, O'Brien L (2005) Do environmental factors affect recruits per spawner anomalies of New England groundfish? ICES J Mar Sci 62:1394-1407

Cardinale M, Hjelm J (2006) Marine fish recruitment variability and climate indices. Mar Ecol Prog Ser 309:307-309

Cayan DR (1992) Latent and sensible heat flux anomalies over the northern oceans: the connection to monthly atmospheric circulation. J Clim 5:354-369

Chouinard GA, Swain DP, Currie L, Poirier G, Rondeau A, Benoît H, Hurlbut T, Daigle D (2003) Assessment of cod in the Southern Gulf of St. Lawrence, February 2003. CSAS Res Doc 2003/015

Clark DS, Gavaris S, Hinze JM (2002) Assessment of cod in Division 4X in 2002. CSAS Res Doc 2002/105

Cury P, Roy C (1989) Optimal environmental window and pelagic fish recruitment success in upwelling areas. Can J Fish Aquat Sci 46:670-680

Cushing DH (1982) Climate and fisheries. Academic Press, London

deYoung B, Rose GA (1993) On recruitment and distribution of Atlantic cod (Gadus morhua) off Newfoundland. Can J Fish Aquat Sci 50:2729-2740

Dickson RR, Brander KM (1993) Effects of a changing wind field on cod stocks of the North Atlantic. Fish Oceanogr 2: 124-153

Dippner J, Ottersen G (2001) Cod and climate variability in the Barents Sea. Clim Res 17:73-82

Drinkwater KF, Myers RA (1987) Testing predictions of marine fish and shellfish landings from environmental variables. Can J Fish Aquat Sci 44:1568-1573

Drinkwater K, Belgrano A, Borja A, Conversi A and 5 others (2003) The response of marine ecosystems to climate variability associated with the North Atlantic Oscillation. In: Hurrell J, Kushnir Y, Ottersen G, Visbeck M (eds) The North Atlantic Oscillation: climatic significance and environmental impact. American Geophysical Union, Washington, DC p 211-234

Frank KT, Petrie BD, Choi JS, Leggett WC (2005) Trophic cascades in a formerly cod-dominated ecosystem. Science 308:1621-1623

Fréchet A, Gauthier J, Schwab P, Bourdages H and 7 others (2003) The status of cod in the northern Gulf of St. Lawrence (3Pn, 4RS) in 2002. CSAS Res Doc 2003/065

Fromentin JM, Planque B (1996) Calanus and environment in the eastern North Atlantic. II. Influence of the North Atlantic Oscillation on C. finmarchicus and C. helgolandicus. Mar Ecol Prog Ser 134:111-118 
Fromentin JM, Stenseth NC, Gjøsæter J, Johannessen T, Planque B (1998) Long-term fluctuations in cod and pollack along the Norwegian Skagerrak coast. Mar Ecol Prog Ser 162:265-278

Furevik T, Nilsen JEØ (2005) Large-scale atmospheric circulation variability and it's impacts on the Nordic Seas ocean climate: a review. In: Drange $H$, Dokken $T$, Furevik $T$, Gerdes R, Berger W (eds) The Nordic Seas: an integrated perspective. Vol 158. American Geophysical Union, Washington DC, p 105-136

Gillett NP, Graf HF, Osborn TJ (2003) Climate change and the North Atlantic Oscillation. In: Hurrell JW, Kushnir Y, Ottersen G, Visbeck M (eds) The North Atlantic Oscillation: climatic significance and environmental impact. American Geophysical Union, Washington DC, p 193-209

Grubbs F (1969) Procedures for detecting outlying observations in samples. Technometrics 11:1-21

Hallett TB, Coulson T, Pilkington JG, Clutton-Brock TH, Pemberton JM, Grenfell BT (2004) Why large-scale climate indices seem to predict ecological processes better than local weather. Nature 430:71-75

Hastie TJ, Tibshirani RJ (1990) Generalized additive models. Chapman \& Hall, London

Healey BP, Murphy EF, Stansbury DE, Brattey J (2003) An assessment of the cod stock in NAFO Divisions 3NO. NAFO SCR Doc 03/59

Helland-Hansen B, Nansen F (1909) The Norwegian Sea. R Dep Trade Nav Ind Rep Norw Fish Mar Invest 2:1-360

Hjermann DØ, Stenseth NC, Ottersen G (2004) The population dynamics of Northeast Arctic cod (Gadus morhua) through two decades: an analysis based on survey data. Can J Fish Aquat Sci 61:1747-1755

Hurrell JW (1995) Decadal trends in the North Atlantic Oscillation: regional temperatures and precipitation. Science 269:676-679

Hänninen J, Vuorinen I, Hjelt P (1999) Climatic factors in the Atlantic control the oceanographic and ecological changes in the Baltic Sea. Limnol Oceanogr 45:703-710

ICES (1996) Report of the North Western Working Group. ICES CM 1996/Assess:15

ICES (2004) Report of the ICES Advisory Committee on Fishery Management and Advisory Committee on Ecosystems, 2004. ICES Advice. Vol. 1 No. 2

ICES (2005a) Report of the ICES Advisory Committee on Fishery Management, Advisory Committee on the Marine Environment and Advisory Committee on Ecosystems, 2005. ICES Advice. Vol. 1-11

ICES (2005b) Spawning and life history information for North Atlantic cod stocks. ICES Coop Res Rep 274

Izhevskii GK (1961) Oceanographic basis of formation of the fisheries productivity of seas. Pishepromizdat, Moscow (Transl. 1964: Israel Progr Sci Transl, Jerusalem)

Izhevskii GK (1964) System basis of prediction of oceanographic conditions and reproduction success of commercial species of fish. VNIRO, Moscow (Transl. 1966: Israel Progr Sci Transl, Jerusalem)

Jarre-Teichmann A, Wieland K, MacKenzie BR, Hinrichsen HH, Plikshs M, Aro E (2000) Stock-recruitment relationships for cod (Gadus morhua L.) in the central Baltic Sea incorporating environmental variability. Arch Fish Mar Res 48:97-123

Lekve K, Ottersen G, Stenseth NC, Gjosaeter J (2002) Length dynamics in juvenile coastal Skagerrak cod: Effects of biotic and abiotic processes. Ecology 83:1676-1688

Liu RY (1988) Bootstrap procedure under some non-i.i.d. models. Ann Stat 16:1696-1708
Mammen E (1993) Bootstrap and wild bootstrap for high dimensional linear models in resampling. Ann Stat 21: 255-285

Mann KH, Drinkwater KF (1994) Environmental influences on fish and shellfish production in the Northwest Atlantic. Environ Rev 2:16-32

Mayo RK, Col L (2005) Gulf of Maine cod. NEFSC Ref Doc 05-13:2.153-152.184

Mohn RK, Fanning LP, MacEachern WJ (1998) Assessment of $4 \mathrm{VsW}$ cod in 1997 incorporating additional sources of mortality. CSAS Res Doc 98/78

Moses T, Keladis GN, Diaz HF, Barry RG (1987) Characteristics and frequency of reversals in mean sea level pressure in the North Atlantic sector and their relationships to longterm temperature trends. J Clim 7:13-30

Myers R (2005) Stock recruitment database. Available at: http://ram.biology.dal.ca/ myers/welcome.html

Myers RA (1998) When do environment-recruitment correlations work? Rev Fish Biol Fish 8:1-21

Myers RA, Barrowman NJ (1996) Is fish recruitment related to spawner abundance? Fish Bull 94:707-724

Myers RA, Mertz G, Barrowman NJ (1995) Spatial scales of variability in cod recruitment in the North Atlantic. Can J Fish Aquat Sci 52:1849-1862

Myers RA, Hutchings JA, Barrowman NJ (1996) Hypotheses for the decline of cod in the North Atlantic. Mar Ecol Prog Ser 138:293-308

O'Brien L, Munroe NJ, Col L (2005) Georges Bank Atlantic cod. NEFSC Ref Doc 05-13:2.2-2.29

Olsen EM, Heino M, Lilly GR, Morgan MJ, Brattey J, Ernande B, Dieckmann U (2004) Maturation trends indicative of rapid evolution preceded the collapse of northern cod. Nature 428:932-935

Ottersen G, Stenseth NC (2001) Atlantic climate governs oceanographic and ecological variability in the Barents Sea. Limnol Oceanogr 46:1774-1780

Ottersen G, Planque B, Belgrano A, Post E, Reid PC, Stenseth NC (2001) Ecological effects of the North Atlantic Oscillation. Oecologia 128:1-14

Ottersen G, Alheit J, Drinkwater K, Friedland K, Hagen E, Stenseth NC (2004) The responses of fish populations to ocean climate fluctuations. In: Stenseth NC, Ottersen G, Hurrell J, Belgrano A (eds) Marine ecosystems and climate variation: the North Atlantic. Oxford University Press, Oxford, p 73-94

Ottersen G, Hjermann D, Stenseth NC (2006) Changes in spawning stock structure strengthen the link between climate and recruitment in a heavily fished cod stock. Fish Oceanogr 15(3):230-232, doi:10.1111/j.1365-2419.2006.00404.x

Parsons LS, Lear WH (2001) Climate variability and marine ecosystem impacts: a North Atlantic perspective. Progr Oceanogr 49:167-188

Planque B, Frédou T (1999) Temperature and the recruitment of Atlantic cod (Gadus morhua). Can J Fish Aquat Sci 56: 2069-2077

Planque B, Batten SD (2000) Calanus finmarchicus in the North Atlantic: the year of Calanus in the context of interdecadal change. ICES J Mar Sci 57:1528-1535

Ricker WE (1954) Stock and recruitment. J Fish Res Board Can 11:559-623

Rodionov SN (1995) Atmospheric teleconnections and coherent fluctuations in recruitment to North Atlantic cod (Gadus morhua) stocks. In: Beamish RJ (ed) Climate change and northern fish populations. Can Spec Publ Fish Aquat Sci 121:45-55

Siegismund F, Schrum C (2001) Decadal changes in the wind forcing over the North Sea. Clim Res 18:39-45 
Solow AR (2002) Fisheries recruitment and the North Atlantic Oscillation. Fish Res 54:295-297

Stenseth NC, Mysterud A (2005) Weather packages: Finding the right scale and composition of climate in ecology. J Anim Ecol 74:1195-1198

Stenseth NC, Mysterud A, Ottersen G, Hurrell JW, Chan KS, Lima M (2002) Ecological effects of climate fluctuations. Science 297:1292-1296

Stenseth NC, Ottersen G, Hurrell JW, Mysterud A, Lima M, Chan KS, Yoccoz NG, Ådlandsvik B (2003) Studying climate effects on ecology through the use of climate indices: the North Atlantic Oscillation, El Niño Southern Oscillation and beyond. Proc R Soc Lond B 270:2087-2096

Stenseth NC, Ottersen G, Hurrell JW, Belgrano A (2004) Marine ecosystems and climate variation: the North Atlantic. Oxford University Press, Oxford

Editorial responsibility: Howard Browman (Associate Editorin-Chief), Storebø, Norway
Templeman W (1972) Year-class success in some North Atlantic stocks of cod and haddock. Int Comm Northw Atl Fish Spec Pub 8:223-238

Vázquez A, Cerviño S (2002) An assessment of the cod stock in NAFO Division 3M. NAFO SCR Doc 02/58

Weijerman M, Lindeboom H, Zuur AF (2005) Regime shifts in marine ecosystems of the North Sea and Wadden Sea. Mar Ecol Prog Ser 298:21-39

Wood SN (2001) mgcv: GAMs and Generalized Ridge Regression for R. R News 1-2:20-25

Wood SN (2004a) Stable and efficient multiple smoothing parameter estimation for generalized additive models. J Am Stat Assoc 99:673-686

Wood SN (2004b) Tensor product smooth interaction terms in Generalized Additive Mixed Models. URL: www.maths. bath.ac.uk/ sw283/simon/papers/tgamm.pdf

Submitted: February 24, 2006; Accepted: May 25, 2006 Proofs received from author(s): September 29, 2006 